University of Texas Rio Grande Valley

ScholarWorks @ UTRGV

\title{
Racial-Ethnic Differences in Social Networks and Perceived Support: Measurement Considerations and Implications for Disparities Research
}

\author{
Melissa Flores \\ University of Arizona \\ John M. Ruiz \\ University of Arizona \\ Christian Goans \\ University of North Texas \\ Bert N. Uchino \\ University of Utah \\ Michiyo Hirai \\ The University of Texas Rio Grande Valley, michiyo.hirai@utrgv.edu \\ Seel next page for addditional authors. \\ Part of the Psychology Commons
}

\section{Recommended Citation}

Flores, M., Ruiz, J., Goans, C., Uchino, B., Hirai, M., Tinajero, R., \& Smith, T. (2020). Racial-Ethnic Differences in Social Networks and Perceived Support: Measurement Considerations and Implications for Disparities Research. Cultural Diversity and Ethnic Minority Psychology, 26(2), 189-199. https://doi.org/10.1037/ cdp0000283

This Article is brought to you for free and open access by the College of Liberal Arts at ScholarWorks @ UTRGV. It has been accepted for inclusion in Psychological Science Faculty Publications and Presentations by an authorized administrator of ScholarWorks @ UTRGV. For more information, please contact justin.white@utrgv.edu, william.flores01@utrgv.edu. 


\section{Authors}

Melissa Flores, John M. Ruiz, Christian Goans, Bert N. Uchino, Michiyo Hirai, Ruben Tinajero, and Timothy W. Smith 
Title Page

Racial-Ethnic Differences in Social Networks and Perceived Support: Measurement Considerations and Implications for Disparities Research

Melissa Flores, John M. Ruiz, Christian Goans, Emily A. Butler, Bert N. Uchino, Michiyo Hirai, Ruben Tinajero, \& Timothy W. Smith

Short title: Racial-ethnic differences in social support

Key words: Race, Ethnicity, Social Support, Social Networks, Measurement Invariance, Health Disparities

Word count: 6,569

\section{Corresponding Author}

Melissa Flores, Ph.D.

Center for the Study of Border Health Disparities

Health Sciences | Psychology

The University of Arizona

1503 E. University Blvd.

PO Box 210068

Tucson, AZ 85721

Phone: 520-621-6320

Fax: 520-621-9306

Email: maflor@email.arizona.edu

John M. Ruiz, Ph.D.

Associate Professor of Psychology

School of Science

The University of Arizona

Tucson, AZ

johnruiz@email.arizona.edu

Christian Goans, M.S.

University of North Texas

Denton, TX

christiangoans@gmail.com

Emily A. Butler, Ph.D.

Professor of Family Studies and Human Development

The University of Arizona

Tucson, AZ

eabutler@email.arizona.edu

Bert N. Uchino, Ph.D.

Chair, Professor of Social and Health Psychology

University of Utah 
Salt Lake City, Utah

bert.uchino@psych.utah.edu

Michiyo Hirai, Ph.D.

Associate Professor of Psychology

The University of Texas, Rio Grande Valley

Rio Grande Valley, TX

michiyo.hirai@utrgv.edu

Ruben Tinajero, M.S.

University of Utah

Salt Lake City, Utah

ruben.tinajero@psych.utah.edu

Timothy W. Smith, Ph.D.

Professor of Clinical and Health Psychology

The University of Utah

Salt Lake City, Utah

tim.smith@psych.utah.edu 
Racial-Ethnic Differences in Social Networks and Perceived Support: Measurement Considerations and Implications for Disparities Research 


\begin{abstract}
Objectives: Racial/ethnic differences in physical/mental health are well documented as being associated with disparities; however, emerging conceptual models increasingly suggest that group differences in social functioning and organization contribute to these relationships. There is little work examining whether racial/ethnic groups respond similarly to classic measures of social networks and perceived support and whether there are significant between-group differences on these measures. Methods: A multisite, cross-sectional study of 2,793 nonHispanic White (NHW), non-Hispanic Black (NHB), and Hispanic participants was conducted using common measures of social networks and perceived support. A confirmatory factor analytic model was used to test for the invariance of factor covariance and mean structures in a three latent constructs model including social network, social provisions, and interpersonal support. Between-group differences in structural and functional support were assessed. Results: We established measurement invariance of the latent representations of these measures suggesting that racial/ethnic groups responded comparably. In direct comparisons, Hispanics and NHWs demonstrated similar levels of network structure and support. In contrast, NHWs reported support advantages on a majority of measures compared to NHBs. Conclusions: Findings support the use of these measures across groups and provide initial support for potential differences in this hypothesized mediator of racial-ethnic health disparities.
\end{abstract}




\section{Introduction}

Social relationships have been consistently predictive of health and well-being. Larger network size, greater satisfaction with the quality of relationships, and having specific social ties such as close friends or a spouse/partner, are broadly associated with greater happiness, life satisfaction, job satisfaction, lower risk of mental and physical illness, and longer life expectancy (Holt-Lunstad, Smith, \& Layton, 2010; Shor, \& Yogev, 2013; Uchino, Bowen, Carlisle, \& Birmingham, 2012; Viswesvaran, Sanchez, \& Fisher, 1999). Racial and ethnic variations in social relationships have often been hypothesized to contribute to well-observed mental and physical health disparities and resilience (Ruiz, Hamann, Mehl, \& O'Connor, 2016). However, there is little published research documenting the makeup of social networks and the type of perceived support across different racial-ethnic groups. In addition, there is an often-ignored question of whether these direct comparisons using a common survey instrument are appropriate given sociocultural differences across racial-ethnic groups. Elucidating any potential differences contributes to existing literature about sociocultural factors related to health disparities and potential mechanisms of resilience in minority groups.

\section{The Case for Invariance Testing}

Racial-ethnic comparisons are commonly performed in studies assessing health disparities. The literature vis-à-vis structural and functional supports relies heavily on validated, self-report measures. However, racial-ethnic comparisons of self-reported measures are based upon the assumption that the conceptual elements measured by surveys have the same notional meaning across groups (Little, 1997). In addition, group comparisons without prior invariance testing may not result in essential mean differences but instead may reflect differences conflated with measured and unmeasured group characteristics (Gregorich, 2006). Thus, invariance testing 
is an essential, yet rarely performed process in racial-ethnic comparisons of validated, self-report measures. Thus, the purpose of our study is to address this critical gap in the literature using a two-aim approach. First, we aim to address the issue of measurement invariance as a way of understanding whether racial/ethnic groups respond similarly to commonly utilized measures of social networks and support. Aim 1 speaks to the potential fidelity of survey measures to ascertain whether between-group comparisons can be accurately estimated given sociocultural differences across Hispanics, Non-Hispanic Blacks (NHBs), and Non-Hispanic Whites (NHWs). The related, second aim is to then directly compare racial-ethnic groups on commonly utilized measures of social networks and support should Aim 1 warrant it.

\section{Structural and Functional Support}

Support in relationships can be understood through two broad categories: structural support, and functional support (Uchino, 2006). Structural support refers to the frequency of encounters with others and the size and structure of social networks. Functional support encompasses specific functions served by others including both perceived and received support. As perceived support is the most common measure of support used and hence has good epidemiological support in links to health and mortality, we chose to focus this study on perceived support (Uchino, Bowen, Kent de Grey, Mikel, \& Fisher, 2018).

Structural Support. Structural support is defined as the infrastructure of one's network (i.e. size, density, etc.) in addition to the frequency of contact with members of one's network. Social networks are the infrastructure of interpersonal relationships focal to an individual (Hill, \& Dunbar, 2003). This infrastructure is affected, and built by the common frequency of contact between the focal individual and their interpersonal supports (Ajrouch, Antonucci, \& Janevic, 2001; Uchino, 2004). The measurement of social networks has included a plethora of techniques 
including whole network approaches whereby all actors in a network are surveyed for information, and self-reported, egocentric network approaches whereby participants name connections to, and between relatives, friends, or acquaintances (Christakis, \& Fowler, 2007; Wasserman, \& Faust, 1994). Others include survey measures such as the Berkman-Syme Social Network Index (SNI; Berkman, \& Syme, 1979), and the Cohen SNI (Cohen, Doyle, Skoner, Rabin, \& Gwaltney, 1997). A commonly utilized measure of structural support is the Cohen SNI including item measures assessing the frequency of contact with others, the composition of one's network, and its size (Cohen, et al., 1997). The Cohen SNI moved beyond the Berkman-Syme SNI as a unique measure of social networks because of its ability to assess three distinct characteristics of a social network. These include network size, number of high contact roles (the number of unique social roles [family member, friend, etc.] in which the respondent has regular contact- also termed network diversity), and the number of embedded networks (the number of network domains in which a respondent is very active). The structure of networks and the frequency of contact with individuals in one's network are associated with both physical and mental health (Kawachi, \& Berkman, 2001; Santini, Koyanagi, Tyrovolas, Mason, \& Haro, 2015, Shor, Roelfs, \& Yogev, 2013). For example, in a meta-analysis examining social connectedness and depression, social isolation or infrequent social contact was associated with a higher risk for depression (Santini, Koyanagi, Tyrovolas, Mason, \& Haro, 2015). In addition, in a meta-analysis of over 50 studies authors found that support from family members as compared to friends was more strongly associated with longevity (Shor, et al. 2013).

Functional Support. Functional support refers to the utility of social relationships; it encompasses both perceived and received domains. A substantial literature linking social integration and health is based on the importance of perceived support. Perceived support is one's 
perception of the extent to which support from one's network would be available if needed and has been more consistently associated with health versus received support (Uchino, et al., 2018). For example, greater perceived support is associated with both physical and mental health outcomes including lower risk for cardiovascular disease (Frasure- Smith et al., 2000) and lower incidence of depression over time (Wright, et al., 2013). In contrast, lower perceived support and loneliness are unique predictors of greater mental and physical health risk (Segrin, \& Passalacqua, 2010).

Perceived support has traditionally been measured using a variety of self-report surveys, including the Interpersonal Support Evaluation List (ISEL). The ISEL may be one of the most widely used perceived support scales with the original scale study being cited over 2,500 times and translated into 10 languages. The ISEL-12 (short-form; Cohen, Mermelstein, Kamarck, \& Hoberman, 1985), has also been widely accepted (Barefoot, et al., 2000; Debnam, Holt, Clark, Roth, \& Southward, 2012). The ISEL-12's key contribution to social support literature is its measurement of various distinct categories of perceived support including: the availability of material aid (tangible), the perceived availability of people with whom one can engage in activities (belonging), and the perceived availability of others with whom to discuss problems (appraisal). Social support as measured by the ISEL has been associated with myriad health outcomes including mortality. For example, in a meta-analysis by Holt-Lunstad and colleagues (2010), the ISEL was included among other measures suggesting that high perceived support was associated with a $50 \%$ increase in the odds of survival (Holt-Lunstad, Smith, \& Layton, 2010).

Another widely utilized, multi-dimensional measure of social support is the Social Provisions Scale (SPS; Russell, \& Cutrona, 1984). Like the ISEL-12, the SPS also measures distinct categories of perceived support. Russell and Cutrona (1984) define these categories as 
"social provisions" including the following subscales: attachment, social integration, reassurance of worth, reliable alliances, guidance, and opportunity for nurturance. Given some conceptual overlap in the types of support measured by the ISEL-12 and SPS subscales, the use of these particular scales was advantageous as we could assess whether these forms of perceived support were similarly associated across racial-ethnic groups. For example, the ISEL-12 subscale tangible support and the SPS subscale reliable alliances both measure the perceived availability of material aid.

\section{Examining Social Networks and Support Across Racial Ethnic Groups}

Racial-ethnic minority groups in United States (US) are often subject to cultural stressors and individual and systematic discrimination (Saleem, et al., 2016). These challenges directly contribute to health disparities, but may also influence social organization, network structures, and social supports (Child, \& Albert, 2018; Smyth, Siriwardhana, Hotopf, \& Hatch, 2015). Some research suggests that minority groups may exhibit networks containing mainly rich, kinship relationships given the history of slavery and colonization in the US (Suarez, et al., 2000, Hedegard, 2018). Given the explicit association between social integration and health, it is prudent to consider both structural and functional supports as contributing factors toward health disparities and/or factors of resilience in minority groups. Our study will begin to fill this critical gap in the literature by examining key aspects of social integration across racial/ethnic groups.

Hispanic Networks and Support. Social networks among Hispanics consist mostly of immediate and extended family members who are bound by cultural values emphasizing the importance of family (Rodriguez, Mira, Paez, \& Myers, 2007). Hispanic households often include extended family more so than their NHW counterparts, potentially giving Hispanics frequent, close contact with extended family members (Sarkisian, Gerena, \& Gerstel, 2007). 
Additionally, in a study of Hispanic college students, cultural values such as marital and parental commitment were associated with smaller network size, suggesting an emphasis placed specifically on familial ties (Archuleta, \& Perry, 2016). Older Hispanics as compared to NHWs are also more likely to rely on support from children (Kim, \& McKenry, 1998). Lastly, broader network ties among Hispanics are fostered by common heritage, shared language, and a sense of collective commitment (Messias, Barrington, \& Lacy, 2012).

Hispanic networks often provide high levels of emotional support and belonging, but may lack in informational and tangible support such as problem-solving (Painter, 2018). For example, in a study by Molina and colleagues (2016), Hispanics reported using social support for emotional encouragement (emotional support) after an abnormal mammogram, however NHWs reported using social support to gain information about diagnostic procedures (informational support).

In spite of various minority-related stressors, Hispanics often show a mortality advantage over other minority groups (e.g. NHBs), as well as NHWs (Ruiz, et al., 2013). Scholars have termed this epidemiological phenomenon the Hispanic Mortality Paradox (Abraido-Lanza, Dohrenwend, Ng-Mak, \& Turner, 1999; Ruiz, et al., 2013). Issues with data reporting, selective immigration (only the healthy immigrate), selective emigration (the unwell return to their home country to die), and positive cultural and familial influences have been suggested as potential explanations for the Hispanic Mortality Paradox (Palloni, \& Arias, 2004). However, data issues and emigration/immigration have since been refuted by contrasting evidence (Abraido-Lanza, et al., 1999; Arias, Eschbach, Schauman, Backlund, \& Sorlie, 2010). Social science scholars have since hypothesized that large social networks and high levels of support are a mediating factor for their mortality advantage and better health (Ruiz, et al., 2016). 
Non-Hispanic Black Networks and Support. Similar to Hispanics, NHBs tend to have more family members in their network compared to NHWs (Ajrouch, Antonucci, \& Janevic, 2001). Black networks have also been described as communal in nature with importance placed on respecting elders (Burton, \& Jarrett, 2000; Harris, \& Molock, 2000). For example, young, African American women with children often rely on natural mentors such as older sisters, aunts or uncles, and grandmothers for support and guidance (Rhodes, Ebert, Fischer, 1992). In a study of college students, African Americans reported higher levels of parental support than NHWs (D'Augelli, \& Hershberger, 1993). Institutional group involvement also seems to facilitate the formation and infrastructure of networks among African Americans (Olphen, et al., 2003). For example, in a study examining differences in social networks and supports, NHBs were more likely than other groups to be involved in both church-related groups as well as political/activism groups (Brown, \& Brown, 2003).

Network size and frequency of contact among NHBs may depend on age related factors (Ajrouch, Antonucci, \& Janevic, 2001; Jay, \& D'Augelli, 1991). Although older NHBs have smaller social networks as compared to NHWs, they engage with their network more compared to NHWs (Ajrouch, et al., 2001). Conversely, in a study of college students, social network size and frequency of contact did not differ across NHBs and NHWs (Jay, \& D'Augelli, 1991). Older NHBs are also more likely to rely on support from children when compared to NHWs who were more likely to rely on non-family members in times of crisis (Kim, \& McKenry, 1998).

Although these studies suggest some racial-ethnic differences in social support and network infrastructure, the topic remains an open question especially as these social factors may be mechanisms for both health disparities and resilience in minority populaces however, no 
studies that we can find address the important measurement question regarding whether comparisons among groups can be made in the first place.

\section{Current Study}

The purpose of this study is to address the gap in literature regarding racial-ethnic differences in social networks and support. Our first aim was to utilize invariance testing to ascertain whether common measures of social support (the SNI, ISEL-12, and the SPS) are answered similarly across three racial/ethnic groups: Hispanics, NHBs, and NHWs. Our second aim was to compare racial/ethnic differences in social network size and perceived social support. Given the literature above, we predicted that Hispanics have a greater social network size when compared to other groups. However, we also predicted that minority groups (i.e. both Hispanics and NHBs), when compared to their NHW counterparts, have less embedded networks given their reliance on familial or kinship networks. As little work has directly tested or measured the number of high contact roles in the context of racial/ethnic comparisons, we offer no formal hypothesis as to which racial/ethnic group may have more or less.

Given the well-established sociocultural differences in needs and values across racial/ethnic groups, and the potential mediating social factors for the Hispanic Mortality Paradox, we hypothesized that differences across groups on specific types of support measured by the ISEL-12 and SPS would be observed for Hispanics. Specifically, Hispanics will show a support advantage over other racial/ethnic groups. In light of the relative paucity of literature addressing differences in perceived support between NHBs and NHWs, we hypothesized that there would be differences in the types of perceived support given group differences in culture and values surrounding support, however, we did not specify any direction.

\section{Method}




\section{Sample}

A common convenience sample was used for both aims. Participants were recruited at four geographically diverse public universities ( 2 in Texas, 1 in Georgia, and 1 in Utah) selected for their racial/ethnic representation. Respondents were not financially compensated, but rather they received research credit for university courses commensurate with 60-90 minutes of survey participation (median survey duration $=62.1$ minutes). The inclusion criteria were: 1$) 18+$ years of age and 2) written and verbal fluency in either English or Spanish. A final sample of 3,283 undergraduates participated in the study, 264 of whom were non-native respondents. Hispanics, NHBs, and NHWs composed $86.3 \%$ of the sample $(N=2,793)$. Other groups (Asian Americans, Native Americans, and multiracial/others) in our sample were too small for invariance statistical tests and thus omitted from our final sample. The relative distribution (Table 1) was 1,118 (40\%) NHW, 378 (13.5\%) NHB, and 1,297 (46.4\%) Hispanic/Latino. Of the 1,297 Hispanics, 164 (12.6\%) were foreign born, 1,078 (83.1\%) were Mexican or of Mexican descent, and 961 (74.1\%) identified as Hispanic White. The mean age of the aggregated sample was $20.9(S D=$ 4.1) years with the majority self-identified as women $(72.3 \%)$. Notably, NHWs were twice as likely than both Hispanics and NHBs to report a household income greater than $\$ 100,000$.

\section{Measures}

Demographics. All participants were surveyed regarding their racial-ethnic identity, gender, age, income, and education.

Social Networks. The Social Network Index (SNI; Cohen, Doyle, Skoner, Rabin, \& Gwaltney, 1997) was used to measure the size, and impact of 12 types of social relationships including spousal-like relationships, parents and parents-in-law, close family members, friends, neighbors, work colleagues, school peers, volunteer-related colleagues, and group memberships. 
The SNI contains three subscales including network diversity measured by the number of highcontact roles, the number of people in a social network, and the number of embedded networksa measure of the number of network domains in which a respondent is very active (e.g. family, volunteering, work, etc.). Example items include the following, "How many other relatives (other than your immediate family) do you feel close to?", and "How many close friends do you have? (Meaning people that you feel at ease with, can talk to about private matters, and can call on for help)." Responses range from '0-7 or more.' The SNI subscales were scored according to the paradigm created by Cohen and colleagues (Cohen, Doyle, Skoner, Rabin, \& Gwaltney, 1997).

The complicated scoring strategies of the SNI prevents accurate assessment of subscale alphas. However, an omnibus scale alpha was calculated using the scored subscales as items (Cronbach's $\alpha=.88$ ). Likewise, to create a latent factor for social networks, each of the scored subscales were used as parcel indicators.

Interpersonal Support. Interpersonal support was measured using the Interpersonal Support Evaluation List-12 (ISEL-12; Cohen, \& Hoberman, 1983). An abbreviated version of the original 40 -item scale was selected to reduce participants' survey fatigue. Participants rated the degree to which they agreed with the 12 items on a 4 -point Likert scale ranging from $0=$ "definitely false" to 3 = "definitely true." Like the 40 -item measure, the 12 -item short form allows for the assessment of three subtypes of support: tangible (the perceived availability of material aid), belonging (the perceived availability of people with whom one can do activities), and appraisal support (perceived availability of others to talk to about problems), omitting the self-esteem subscale. Example items include "If I were sick, I could easily find someone to help me with my daily chores", and "If a family crisis arose, it would be difficult to find someone who 
could give me good advice about how to handle it." The ISEL-12 as the original long form is widely utilized and has been shown to have good construct and convergent validity as it positively correlates with social network integration, and negatively correlates with negative affect and perceived social stress (Cohen, \& Hoberman, 1983). Internal consistency within our sample was adequate, $($ Cronbach's $\alpha=.87 ; \alpha$ subscale range $=0.64-0.76)$. A latent variable called interpersonal support was created using the three support subscales, tangible, belonging, and appraisal as parcel item indicators.

Social Provisions. The Social Provisions Scale (SPS; Russell, Cutrona, Rose, \& Yurko, 1984) can be conceptualized as a complement to the ISEL-12. The measure operationalizes Weiss's (1974) focus on six social provisions that an individual may receive from others. We used the SPS to measure the extent to which participants' social ties offer specific dimensions of social support. The SPS is a 24-item scale with responses rated on a 4-point Likert scale ranging from 1 = "strongly disagree", to 4 = "strongly agree". Individual items assess the degree to which the statement defines a participant's social network. The dimensions of social support are represented by six subscales including attachment (emotional support and feelings of closeness with others), social integration (support from wider network members), reassurance of worth (self-esteem support), reliable alliance (tangible support), guidance (informational support), and opportunity for nurturance (the respondent offering support to or helping others). Example items include "There are people I can depend on to help me if I really need it.", and "I have close relationships that provide me with a sense of emotional security and well-being.". In the current study, the SPS had excellent to adaquate internal consistency (omnibus Cronbach's $\alpha=0.94$; subscale $\alpha$ range $=0.70-0.83$ ). A latent factor called social provisions was created by including the six subscales as parcel item indicators. 


\section{Procedure}

This data collection was part of a larger survey. All surveys were conducted online via RedCap and Qualtrics. Upon opening our survey, participants were asked to choose either an English or Spanish language preference followed by an opportunity to read and provide informed consent. Of the total survey respondents, only 55 (1.7\%) opted for a Spanish version of the survey. Given the small percentage of participants that utilized the Spanish version, $(\sim 4 \%$ of Hispanics) we opted to include these responses in the final analysis. Consented participants moved on to the online survey. Average completion time was less than one hour.

\section{Statistical Analyses}

All statistical analyses were conducted in R statistical computing environment (R Core Team, 2015). Aim 1: To examine the factorial structure of each scale we used a confirmatory factor analysis (CFA) with each scored subscale as parcel item indicators of their respective latent construct: social networks, interpersonal support, and social provisions. We chose to use parcels vs. items for two key reasons, 1) the Social Network Index has a complex scoring paradigm that does not lend itself to the use of item indicators in latent contexts, and 2) parcels greatly reduce the number of parameters fit in an analysis. Given our smaller sample of African American/Black individuals in our analysis, we chose to fit parcels to retain this group. Using parcels as a measurement technique has several advantages over using item indicators. Parcels (when compared to items) tend to have higher reliability, higher ratio of common-to-unique factor variance, less distributional violations, and more interval equality (Little, Rhemtulla, Gibson, \& Schoemann, 2013). To determine overall model fit we assessed the following: the significance of the Chi-square statistic, the Comparative Fit Index (CFI) greater than .95 (.90), the root mean square error approximation (RMSEA) less than .05 (.08), and the standardized root 
mean squared residual (SRMR) less than 0.05 (.08), indicating good (or acceptable) model fit (Hu, \& Bentler, 1999; Little, 2013). To assess whether Hispanics, NHBs, and NHWs responded similarly to the measures of structural and functional social support, a confirmatory factor analytic model was used to test for the invariance of factor covariance and mean structures in a three latent construct model: social network, social provisions, and interpersonal support. Gender, and income, were included as control variables as social support has been shown to vary across these constructs (Turner, \& Merino, 1994). Religious affiliation was also included as a control because of its close association with social support among NHBs (Brown \& Brown, 2003). Invariance tests by nativity were attempted among Hispanics, however, given the small sample of foreign-born Hispanics we were unable to proceed. Aim 2: Following tests of invariance, mean comparisons were calculated using fifteen multilevel models with each social variable subscale and omnibus totals as outcome variables. Multilevel models were utilized to control for the random effect of geographic region/community. Homoscedasticity of residual variances for each model were assessed and confirmed. Alpha levels between group comparisons were adjusted using the Bonferroni correction of $.05 / 15=.0033$.

\title{
Results
}

\begin{abstract}
Aim One
Table 2 displays total and subscale means and standard deviations by race/ethnicity. Bivariate correlations between all item indicators and omnibus total scores are displayed in Table 3. Invariance testing provides an answer to "whether or not, under different conditions of observing and studying phenomena, measurements yield measures of the same attributes" (Horne and McArdle, 1992, p.117). To ascertain whether Hispanic and non-Hispanic groups could be compared, we first tested our model within a multi-group CFA to examine the factorial
\end{abstract}


invariance across Hispanic and non-Hispanic participants. We then tested NHWs against NHBs, Hispanics against NHWs, and Hispanics against NHBs. See Table 4 for model fit statistics for the measurement model and the multi-group CFAs including configural, weak factorial, and strong factorial invariance. We found that each constraint (weak and strong factorial) was tenable as the change in CFI was $<.01$ for NHW and NHBs (CFI $=0.955,0.954)$, for NHWs and Hispanics (CFI $=0.955,0.953)$, and for NHBs and Hispanics (CFI = 0.955, 0.952; Little, 1997). Thus, we concluded that the probability of aggregated responses is not different across groups and these measures may be compared.

\author{
Aim Two \\ We assessed between group differences using multilevel models to control for the \\ random effect of geographic location. The intracluster correlation coefficients (ICC)s for each \\ outcome represent the within-site variance in each outcome (see Table 5). Overall, ICCs ranged \\ from 0.01 to 0.55 , although interestingly, ICCs among social network models were greater than \\ those calculated from models predicting functional social support (ISEL-12 and the SPS). \\ Structural Support. As mentioned above, an alpha level of $p<.0033$ was set to account \\ for multiple tests. Our hypothesis that Hispanics would have larger social networks (as measured \\ by the SNI) when compared to other racial-ethnic groups was not supported. Racial-ethnic \\ identity was not a significant predictor of the number of people in one's network, and between- \\ group difference models revealed no significant differences between NHWs and Hispanics, nor \\ between Hispanics and NHBs. Non-Hispanic Blacks reported less people in one's network when \\ compared to NHWs, $b=-1.69, t(2690)=-2.89, p=0.003,95 \%$ CI $(-1.85,-0.06)$. See Table 6 \\ for a comprehensive list of racial-ethnic contrasts.
}


Racial-ethnic identity was not a significant predictor of embedded networks, $F(2,2690)=$ $3.62, p=0.02$, however, in support of our hypothesis, NHWs had significantly more embedded networks than Hispanics, $b=0.18, t(2690)=3.30, p=0.001,95 \%$ CI $(0.07,0.29)$. Racial-ethnic identity was not significantly associated with the number of high contact roles, and there were no significant differences in the number of high contact roles across racial ethnic groups.

Religious affiliation was significantly associated with all social network subscale measures such that being associated with a religious affiliation was associated with higher scores on the following subscales: number of people in a network, high contact roles, and embedded networks (all $b \mathrm{~s}>0.80$, all $p \mathrm{~s}<0.001$ ). Higher reported income was associated with more people in a network, $b=.20, t(2690)=4.46, p<0.001,95 \% \mathrm{CI}(0.11,0.29)$. Lastly, women reported significantly more high contact roles than men, $b=0.20, t(2690)=2.90, p<0.001,95 \% \mathrm{CI}$ $(0.07,0.34)$.

Functional Support. Our hypothesis that Hispanics would report greater support than other racial/ethnic groups was only partially supported. In addition, we hypothesized that there would be racial-ethnic differences across the ISEL-12 subscales. This hypothesis also was only partially supported. In partial support of our hypothesis, NHBs, reported less perceived appraisal support than NHWs, $b=-0.50, t(2670)=-2.91, p=.003,95 \% \mathrm{CI}(-0.84,-0.16)$. As expected, perceived tangible support was significantly related to racial-ethnic identity, $F(2,2668)=9.29, p$ $=0.001$. However, contrasts revealed that Hispanics did not differ from other groups (NHWs and NHBs), but, NHBs reported significantly less tangible support than NHWs, $b=-0.67, \mathrm{t}(2668)=$ $-4.25, \mathrm{p}<.001,95 \% \mathrm{CI}(-0.97,-0.36)$. Contrary to our hypothesis, racial-ethnic identity was not associated with perceived belonging support, and no racial-ethnic differences emerged in our contrasts. 
Being a woman and reporting a higher income were associated with higher appraisal support, belonging support, and tangible support (all $b \mathrm{~s}>0.05$, all $p \mathrm{~s}<.003$ ). Religious affiliation was associated with more reported appraisal support, and belonging support (all $b$ s $>$ 0.31 , all $p \mathrm{~s}<.001)$

Similarly, our hypothesis that Hispanics would report greater support across the SPS subscales was only partially supported. As expected, racial-ethnic identity was a significant predictor of the social provision, attachment, $F(2,2633)=13.80, p<0.001$, and NHBs reported having lower levels of attachment provisions when compared to Hispanics, $b=-0.47, t(2633)=$ $2.98, p=0.003,95 \%$ CI $(-0.78,-0.16)$, as well as NHWs $b=-0.80, t(2633)=-4.88, p=0.001$, CI $(-1.11,-0.48)$. Contrary to our hypothesis, NHWs reported higher attachment when compared to Hispanics $b=0.32, t(2633)=2.93, p=0.003,95 \% \mathrm{CI}(0.11,0.54)$. While racial-ethnic identity was not significantly related to social integration $F(2,2624)=4.91, p=0.008$, NHBs reported being less socially integrated than NHWs, $b=-0.52, t(2624)=-3.25, p=0.001,95 \%$ CI $(-0.83,-0.21)$. Contrary to our hypothesis, there were no significant differences between NHWs and Hispanics, nor between Hispanics and NHBs.

Racial-ethnic identity was significantly related to reliable alliances, $F(2,2631)=11.34, p$ $<0.001$, and NHBs reported less reliable alliances when compared to NHWs, $b=-0.74, t(2631)$ $=-4.62, p<.001,95 \%$ CI $(-1.05,-0.43)$. As predicted, racial-ethnic identity was significantly associated with guidance, $F(2,2629)=21.53, p<0.001$, and Hispanics reported significantly higher guidance than NHBs $b=-0.45, t(2629)=-2.94, p=0.003,95 \%$ CI $(0.24,0.66)$, but NHWs presented a support advantage over Hispanics for guidance, $b=0.45, \mathrm{t}(2629)=2.94, \mathrm{p}<$ $0.001,95 \% \mathrm{CI}(0.24,0.66)$. In addition, NHBs reported significantly less guidance support than NHWs, $b=-0.90, t(2629)=-5.75, p<0.001,95 \%$ CI $(-1.20,-0.59)$. Opportunity for nurturance 
was not significantly related to racial-ethnic identity, $F(2,2633)=5.10, p=0.006$, however, NHBs reported less opportunity for nurturance than NHWs, $b=-0.55, t(2633)=-3.45, p=.001$, $95 \%$ CI $(-0.86,-0.24)$. Lastly, racial-ethnic identity was not associated with reassurance of worth support, nor did any racial-ethnic differences emerge in our contrasts.

Higher income was positively associated with all subscales of the Social Provisions Scale (SPS) with the exception of opportunity for nurturance (all $b \mathrm{~s}>0.05$, all $p \mathrm{~s}<.001$ ). Being a woman was associated with higher levels of all subscales of the SPS (all $b \mathrm{~s}>0.52$, all $p \mathrm{~s}<.001$ ). Lastly, being affiliated with a religious institution was associated with all subscales of the SPS with the exception of reliable alliance and reassurance of worth (all $b \mathrm{~s}>0.37$, all $p \mathrm{~s}<.001$ ). $<$ Table 4>

$<$ Table 5>

\section{Discussion}

Ultimately, the purpose of a survey measure is to capture a specific social phenomenon. In our study, we utilized survey measures that capture aspects of social support using items and more broadly, subscales in which the phenomena are reflected. Aim 1: In our study, we found evidence (i.e. measurement invariance) that interpersonal support, social provisions, and social networks do not vary systematically across groups; meaning that potential statistical differences across groups are not due systematic bias in the way the measure was written. Next (Aim 2), we tested for between-group differences on the subscales and total scores of the SNI, ISEL-12, and SPS. Overall, the majority of differences found across the groups were between NHBs and NHWs, with NHWs presenting a support advantage on several subscale measures of both structural and functional support. Hispanics presented a support advantage over NHBs only on a few measures of functional support. In addition, NHWs and Hispanics had similar levels of 
support across both structural and functional supports; however, NHWs exhibited a support advantage in a few areas.

This appears to be one of the first studies to establish measurement invariance across racial-ethnic groups on classic measures of structural and functional support, and to assess between-group differences on these measures. Our results both support and contradict findings in previous research. Hispanics reported lower attachment support (SPS) than NHWs, which contradicts previous research that suggests Hispanics' feelings of closeness toward family (familism) are typically higher than NHWs (Campos, Perez, \& Guardino, 2016). Given that NHWs reported having more embedded networks than Hispanics, this may indicate more opportunities for NHWs to feel attached or close to a wider range of people. Hispanics also reported lower guidance support (SPS) when compared with NHWs. This result corroborates some work showing that Hispanics tend to provide emotional support as opposed to informational or guidance support after receiving an abnormal mammogram (Molina, et al., 2016). Despite the unobserved mean differences across these groups, some groups may be more sensitive to the influence of these social factors given cultural values. These differences may manifest as greater effect sizes when examining their relation to health-related outcomes such as inflammation, etc. In addition, as our sample consists only of university students, their level of education may also bias our results. For example, having a more education is typically associated with larger networks as well as greater social participation (Child, \& Albert, 2018; Hedegard, 2018), however, having greater education has also been associated with being less likely to have someone to call in times of stress (Kim \& McKenry, 1998).

Young non-Hispanic Black respondents had smaller networks (SNI) than their NHW peers, which studies of both adult and older African Americans that also reported smaller social 
networks than NHWs (Ajrouch, et al., 2001; Hedegard, 2018). In addition, NHB respondents reported less tangible and appraisal support (ISEL-12), as well as less attachment, social integration, and reliable alliances support (SPS) when compared with NHWs.

Notionally, tangible supports (ISEL-12) are synonymous with reliable alliances (SPS). With regard to tangible support (ISEL-12) and reliable alliances (SPS), a similar study found that even after controlling for need and income, African American/Black individuals were unlikely to provide financial aid to their kinship or broader social ties (Jayakody, 1998). However, these supports also include services such as car rides, or providing meals, etc., and less is known about racial/ethnic comparisons for these behaviors, specifically in young adult populations. In addition, the relative differences in appraisal (ISEL-12) and attachment (SPS) support between NHBs and NHWs may be related to cultural differences in their perceived importance of providing peer support. For example, Samter and colleagues (1997) found that African American women were less likely to endorse the importance of providing support to peers in times of distress when compared to their NHW peers (Samter, Whaley, Mortenson, \& Burleson, 1997). Opportunity for nurturance (SPS) is unique in that this is the only subscale that measures support given by the respondent to others. Both minority groups reported less opportunity for nurturance than NHWs, and NHBs reported less opportunity for nurturance than Hispanics. This disparity may reflect different sociocultural values or needs, for example, in a racial-ethnic comparison of social support in college students, Kenny and Stryker (1996) found that minority students had different support needs than White students including relying on others for support (Kenny, \& Stryker, 1996). Although our findings may indicate differences in sociocultural norms and needs in young adults, they add to the amassed literature documenting consistent social and structural 
disparities found when comparing minorities to dominant groups, especially in the case of NHBs.

\section{Implications for Health Disparities and Future Research}

Our findings point to several implications for health disparities research. First, our findings provide evidence that commonly utilized measures of perceived social support (SNI, ISEL-12, and SPS) are invariant across three racial-ethnic groups of young adults. As social support is critical to health, future studies may seek to illuminate how this mechanism varies across minority and dominant groups. These results support the current and future studies that seek to compare perceived social support (as measured by the aforementioned measures) across racial-ethnic groups.

Although our sample suggests a support disparity for young NHBs when compared with NHWs, it also shows that despite income, gender, and religious affiliation, young Hispanics report similar levels of support when compared with their NHW peers. Given the profound importance of social support and integration on health, this finding may partially explain some health and longevity trends illuminated by Hispanic Paradox scholars. However, given our homogenous age range, it is prudent to examine potential racial-ethnic differences across the lifespan in future work. Previous research also suggests that ethnic minorities value their interpersonal relationships more so than NHWs (Plant, \& Sachs-Ericsson, 2004). Social support in Hispanics, although similar to NHWs, may be more valued, and thus more potent, or provide more health benefits than in NHWs. For example, Barger and Uchino (2017) found that Hispanics had lower mortality risk for all levels of social integration above the lowest, as opposed to their NHW and NHB counterparts that only showed this effect in the highest levels of integration (Barger \& Uchino, 2017). Additionally, other variables may interact with social 
support to bolster health outcomes such as the endorsement of familism and other Hispanic cultural values, as well as family-level emotion regulation or communal coping, and age (Ruiz, Sbarra, \& Steffen, 2018). Similarly, the general support advantage found in NHWs when compared to NHBs may also need further parsing such that NHBs may place more value on church related interpersonal relationships and this may vary by age (Taylor, Chatters, Hardison, \& Riley, 2001).

\section{Limitations and Future Directions}

Although we utilized sophisticated methods to assess between-group differences in social support (i.e. invariance testing, and controlling for the random effect of geography), our study does have limitations. Most notably, we utilize a cross-sectional, convenience university sample, which provides a homogenous age and education group. Likewise, our sample of NHBs was approximately one third of other racial-ethnic groups. Although, not an issue statistically, this under-representation does hinder our ability to generalize to the broader NHB young adult community. We were also unable to test invariance across nativity, origin (Mexico, Puerto Rico, etc.), or race in Hispanic respondents due to sample size limitations. Invariance tests by these important sociodemographic factors are needed in future work. In addition, the majority marital status of our sample was single, making these results less generalizable to the population at large. This study also does not assess other racial-ethnic groups and thus is not wholly inclusive of the diverse populaces in the US. A large community sample over time would provide a more diverse sample with a representative age-range as well as individuals with a wider range of educational attainment. Lastly, this work focuses on perceived support and does not assess other dimensions of social capital and support such as received support. Future work is needed to assess these aspects of social capital and support. We see this work as valuable for warranting a broader, 
more diverse community study as measurement invariance here in this study was found. In addition, we would have liked to incorporate more culturally sensitive measures of social support as prototypical measures of support may be limited in capturing nuanced cultural differences.

Overall, the field of social support may benefit from extending beyond the common measures tested here, to capture culturally specific forms of support such as family and church supports. In addition, different approaches to analysis may uncover other important aspects of social network structures (e.g. social network analysis). Social scientists may also benefit from thinking about culture-specific moderators such as religious affiliation, neighborhood effects, and nativity.

This study exemplifies the need to assess whether measures capturing social phenomena are culturally biased and whether these potential biases influence our notions about health disparities. Further research in this area will push science toward a more culturally informed health perspective. 


\section{References}

Abraido-Lanza, A. F., Dohrenwend, B. P., Ng-Mak, D. S., \& Turner, J. B. (1999). The Latino mortality paradox: a test of the" salmon bias" and healthy migrant hypotheses. American Journal of Public Health, 89(10), 1543-1548.

Ajrouch, K. J., Antonucci, T. C., \& Janevic, M. R. (2001). Social networks among blacks and whites the interaction between race and age. The Journals of Gerontology Series B: Psychological Sciences and Social Sciences, 56(2), S112-S118.

Aranda, M. P., Ray, L. A., Snih, S. A., Ottenbacher, K. J., \& Markides, K. S. (2011). The protective effect of neighborhood composition on increasing frailty among older Mexican Americans: A barrio advantage?. Journal of Aging and Health, 23(7), 1189-1217.

Arias, E., Eschbach, K., Schauman, W. S., Backlund, E. L., \& Sorlie, P. D. (2010). The Hispanic mortality advantage and ethnic misclassification on US death certificates. American Journal of Public Health, 100(S1), S171-S177.

Ayón, C. and Naddy, M. B. G. (2013), Latino immigrant families’ social support networks: strengths and limitations during a time of stringent immigration legislation and economic insecurity. Journal Community Psychology, 41(3) 359-377. doi:10.1002/jcop.21542.

Barefoot, J. C., Brummett, B. H., Clapp-Channing, N. E., Siegler, I. C., Vitaliano, P. P., Williams, R. B., \& Mark, D. B. (2000). Moderators of the effect of social support on depressive symptoms in cardiac patients. The American Journal of Cardiology, 86(4), 438-442.

Barger, S. D., \& Uchino, B. N. (2017). Racial and ethnic variation in the association of social integration with mortality: Ten-year prospective population-based US study. Scientific Reports, 7(43874) 1-8. 
Burton, L. M., \& Jarrett, R. L. (2000). In the mix, yet on the margins: The place of families in urban neighborhood and child development research. Journal of Marriage and Family, 62(4), 1114-1135.

Berkman, L. F. \& Glass, T. (2000). Social integration, social networks, social support, and health. In L. F. Berkman \& I. Kawachi (Eds.), Social epidemiology: (pp. 137-173). New York, NY: Oxford University Press.

Brown, R. K., \& Brown, R. E. (2003). Faith and works: Church-based social capital resources and African American political activism. Social Forces, 82(2), 617-641.

Campos, B., Perez, O. F. R., \& Guardino, C. (2016). Familism: A cultural value with implications for romantic relationship quality in US Latinos. Journal of Social and Personal Relationships, 33(1), 81-100.

Chang, M. H., Moonesinghe, R., Athar, H. M., \& Truman, B. I. (2016). Trends in disparity by sex and Race/Ethnicity for the leading causes of death in the United States: 1999-2010. Journal of Public Health Management and Practice, 22(1), S13-S24.

Child, S. T., \& Albert, M. A. (2018). Social Networks and Health Outcomes: Importance for Racial and Socioeconomic Disparities in Cardiovascular Outcomes. Current Cardiovascular Risk Reports, 12(12), 12-30.

Christakis, N. A., \& Fowler, J. H. (2007). The spread of obesity in a large social network over 32 years. New England Journal of Medicine, 357(4), 370-379.

Cohen, S., Doyle, W. J., Skoner, D. P., Rabin, B. S., and Gwaltney, J. M., Jr. (1997). Social ties and susceptibility to the common cold. Journal of the American Medical Association, 278(15), 1232-1232.

Cohen, S., \& Hoberman, H. (1983). Positive events and social supports as buffers of life change stress. Journal of Applied Social Psychology, 13(2), 99-125. 
D'Augelli, A. R., \& Hershberger, S. L. (1993). African American undergraduates on a predominantly White campus: Academic factors, social networks, and campus climate. The Journal of Negro Education, 62(1), 67-81.

Debnam, K., Holt, C. L., Clark, E. M., Roth, D. L., \& Southward, P. (2012). Relationship between religious social support and general social support with health behaviors in a national sample of African Americans. Journal of Behavioral Medicine, 35(2), 179-189.

Falcon, L. M. (1995). Social networks and employment for Latinos, Blacks, and Whites. New England Journal of Public Policy, 11(1), 17-28.

Garcia, C. (2005). Buscando trabajo: Social networking among immigrants from Mexico to the United States. Hispanic Journal of Behavioral Sciences, 27(1), 3-22.

Gregorich, S. E. (2006). Do self-report instruments allow meaningful comparisons across diverse population groups? Testing measurement invariance using the confirmatory factor analysis framework. Medical Care, 44(11 Suppl 3), S78-S94.

Gonzalez, J. S., Penedo, F. J., Antoni, M. H., Durán, R. E., McPherson-Baker, S., Ironson, G., ... \& Schneiderman, N. (2004). Social support, positive states of mind, and HIV treatment adherence in men and women living with HIV/AIDS. Health Psychology, 23(4), 413418.

Hedegard, D. (2018). Why do Blacks have smaller social networks than whites? The mechanism of racial identity strength. Ethnic and Racial Studies, 41(14), 2464-2484.

Hill, R. A., \& Dunbar, R. I. (2003). Social network size in humans. Human Nature, 14(1), 53-72.

Horn, J. L. \& McArdle, J. J. (1992). A practical and theoretical guide to measurement invariance in aging research. Experimental Aging Research 18(3): 117-144. 
Holt-Lunstad, J., Smith, T. B., \& Layton, J. B. (2010). Social relationships and mortality risk: a meta-analytic review. PLoS Medicine, 7(7), 1-20.

Hu, L. T., \& Bentler, P. M. (1999). Cutoff criteria for fit indexes in covariance structure analysis: Conventional criteria versus new alternatives. Structural Equation Modeling: a Multidisciplinary Journal, 6(1), 1-55.

Hurtado-de-Mendoza, A., Gonzales, F. A., Serrano, A., \& Kaltman, S. (2014). Social isolation and perceived barriers to establishing social networks among Latina immigrants. American Journal of Community Psychology, 53(1-2), 73-82.

Jay, G. M. and D'Augelli, A. R. (1991), Social support and adjustment to university life: A comparison of African-American and White freshmen. Journal of Community Psychology, 19(2), 95-108.

Kenny, M. E., \& Stryker, S. (1996). Social network characteristics and college adjustment among racially and ethnically diverse first-year students. Journal of College Student Development, 37(6), 649-658.

Kim, H. K., \& McKenry, P. C. (1998). Social networks and support: a comparison of African Americans, Asian Americans, Caucasians, and Hispanics. Journal of Comparative Family Studies, 29(2), 313-334.

Little, T. D. (1997). Mean and covariance structues (MACS) analyses of cross-cultural data: Practical and theoretical issues. Multivariate Behavioral Research, 32(1), 53-76.

Little, T. D., Rhemtulla, M., Gibson, K., \& Schoemann, A. M. (2013). Why the items versus parcels controversy needn't be one. Psychological Methods, 18(3), 285-300.

Messias, D. K. H., Barrington, C., \& Lacy, E. (2012). Latino social network dynamics and the Hurricane Katrina disaster. Disasters, 36(1), 101-121. 
Molina, Y., Hohl, S. D., Nguyen, M., Hempstead, B. H., Weatherby, S. R., Dunbar, C., ... \& Ceballos, R. M. (2016). Ethnic differences in social support after initial receipt of an abnormal mammogram. Cultural Diversity and Ethnic Minority Psychology, 22(4), 588593.

Mulvaney-Day, N. E., Alegría, M., \& Sribney, W. (2007). Social cohesion, social support, and health among Latinos in the United States. Social Science \& Medicine, 64(2), 477-495. doi: http://dx.doi.org/10.1016/j.socscimed.2006.08.030.

Nguyen, A. W., Chatters, L. M., Taylor, R. J., \& Mouzon, D. M. (2015). Social support from family and friends and subjective well-being of older African Americans. Journal of Happiness Studies, 17(3), 959-979.

Olphen, J., Schulz, A., Israel, B., Chatters, L., Klem, L., Parker, E., \& Williams, D. (2003). Religious involvement, social support, and health among African-American women on the east side of Detroit. Journal of General Internal Medicine, 18(7), 549-557.

Painter, T. M. (2018). Social support networks: An underutilized resource for the prevention of HIV and other sexually transmitted diseases among Hispanic/Latino migrants and immigrants. Journal of Health Care for the Poor and Underserved, 29(1), 44-57.

Plant, E. A., \& Sachs-Ericsson, N. (2004). Racial and ethnic differences in depression: the roles of social support and meeting basic needs. Journal of Consulting and Clinical Psychology, 72(1), 41-52.

R Core Team (2015). R: A language and environment for statistical computing. R Foundation for Statistical Computing, Vienna, Austria. URL https://www.R-project.org/. 
Rodriguez, N., Mira, C. B., Paez, N. D., \& Myers, H. F. (2007). Exploring the complexities of familism and acculturation: Central constructs for people of Mexican origin. American Journal of Community Psychology, 39(1-2), 61-77.

Ruiz, J. M., Hamann, H. A., Mehl, M. R., \& O’Connor, M. F. (2016). The Hispanic health paradox: From epidemiological phenomenon to contribution opportunities for psychological science. Group Processes \& Intergroup Relations, 19(4), 462-476.

Ruiz, J. M., Sbarra, D., \& Steffen, P. R. (2018). Hispanic ethnicity, stress psychophysiology and paradoxical health outcomes: A review with conceptual considerations and a call for research. International Journal of Psychophysiology. 131, 24-29.

Ruiz, J. M., Steffen, P., \& Smith, T. B. (2013). Hispanic mortality paradox: a systematic review and meta-analysis of the longitudinal literature. American Journal of Public Health, 103(3), e52-e60.

Rhodes, J. E., Ebert, L., \& Fischer, K. (1992). Natural mentors: An overlooked resource in the social networks of young, African American mothers. American Journal of Community Psychology, 20(4), 445-461.

Russell, D., Cutrona, C. E., Rose, J., \& Yurko, K. (1984). Social and emotional loneliness: an examination of Weiss's typology of loneliness. Journal of Personality and Social Psychology, 46(6), 1313-1321.

Saleem, R., Vaswani, A., Wheeler, E., Maroney, M., Pagan-Ortiz, M., \& Brodt, M. (2016). The effects of structural violence on the well-being of marginalized communities in the United States. Journal of Pedagogy, Pluralism, and Practice, 8(1), 181-204. 
Samter, W., Whaley, B. B., Mortenson, S. T., \& Burleson, B. R. (1997). Ethnicity and emotional support in same- sex friendship: A comparison of Asian- Americans, AfricanAmericans, and Euro- Americans. Personal Relationships, 4(4), 413-430.

Sarkisian, N., Gerena, M., \& Gerstel, N. (2007). Extended family integration among Euro and Mexican Americans: Ethnicity, gender, and class. Journal of Marriage and Family, $69(1), 40-54$

Segrin, C., \& Passalacqua, S. A. (2010). Functions of loneliness, social support, health behaviors, and stress in association with poor health. Health Communication, 25(4), 312322.

Shor, E., Roelfs, D. J., \& Yogev, T. (2013). The strength of family ties: A meta-analysis and meta-regression of self-reported social support and mortality. Social Networks, 35(4), 626-638.

Smith, S. S., \& Moore, M. R. (2000). Intraracial diversity and relations among AfricanAmericans: Closeness among black students at a predominantly white university. American Journal of Sociology, 106(1), 1-39.

Suarez, L., Ramirez, A. G., Villarreal, R., Marti, J., McAlister, A., Talavera, G. A., ... \& PerezStable, E. J. (2000). Social networks and cancer screening in four US Hispanic groups. American Journal of Preventive Medicine, 19(1), 47-52.

Taylor, R. J., Chatters, L. M., Hardison, C. B., \& Riley, A. (2001). Informal social support networks and subjective well-being among African Americans. Journal of Black Psychology, 27(4), 439-463. 
Taylor, R. J., Chatters, L. M., Woodward, A. T., \& Brown, E. (2013). Racial and ethnic differences in extended family, friendship, fictive kin and congregational informal support networks. Family Relations, 62(4), 609-624.

Thornton, M. C., Taylor, R. J., \& Chatters, L. M. (2013). African American and Black Caribbean mutual feelings of closeness: findings from a national probability survey. Journal of Black Studies, 44(8), 798-828.

Turner, R. J., \& Marino, F. (1994). Social support and social structure: A descriptive epidemiology. Journal of Health and Social Behavior, 35(3), 193-212.

Uchino, B. N., Bowen, K., Carlisle, M., \& Birmingham, W. (2012). Psychological pathways linking social support to health outcomes: A visit with the "ghosts" of research past, present, and future. Social Science \& Medicine, 74(7), 949-957.

Uchino, B. N., Bowen, K., de Grey, R. K., Mikel, J., \& Fisher, E. B. (2018). Social support and physical health: Models, mechanisms, and opportunities. In Fisher E. et al.

(Eds) Principles and Concepts of Behavioral Medicine (pp. 341-372). Springer, New York, NY.

Viswesvaran, C., Sanchez, J. I., \& Fisher, J. (1999). The role of social support in the process of work stress: A meta-analysis. Journal of Vocational Behavior, 54(2), 314-334.

Weiss, R. S. (1974). The provisions of social relationships. In Z. Rubin (Ed.), Doing Unto Others (pp. 17-26). Englewood Cliffs, NJ: Prentice-Hall.

Wright, K. B., Rosenberg, J., Egbert, N., Ploeger, N. A., Bernard, D. R., \& King, S. (2013). Communication competence, social support, and depression among college students: a model of Facebook and face-to-face support network influence. Journal of Health Communication, 18(1), 41-57. 
Tables

Table 1.

Demographic information by racial/ethnic group*

\begin{tabular}{lcccc}
\hline & NHW & NHB & Hispanic & Total \\
& $\mathrm{N}=1118$ & $\mathrm{~N}=378$ & $\mathrm{~N}=1297$ & $\mathrm{~N}=2,793$ \\
\hline Age Mean(SD) & $21.42(4.58)$ & $21.31(4.47)$ & $20.29(3.32)$ & $20.9(4.1)$ \\
\hline \multicolumn{5}{l}{} \\
\hline Gender N(\%) & & & \\
\hline Male & $304(27.4 \%)$ & $110(29.1 \%)$ & $355(27.5 \%)$ & $769(27.7 \%)$ \\
Female & $806(72.6 \%)$ & $268(70.9 \%)$ & $937(72.5 \%)$ & $2011(72.3 \%)$ \\
Marital Status N(\%) & & & \\
\hline Single & & & \\
Married & $934(83.5 \%)$ & $351(93.1 \%)$ & $1173(90.4 \%)$ & $2458(88 \%)$ \\
Living with partner & $95(8.5 \%)$ & $11(2.9 \%)$ & $61(4.7 \%)$ & $167(6 \%)$ \\
Divorced & $73(6.5 \%)$ & $11(2.9 \%)$ & $51(3.9 \%)$ & $135(4.8 \%)$ \\
Widowed & $15(1.3 \%)$ & $4(1.1 \%)$ & $10(<1 \%)$ & $29(1 \%)$ \\
& $1(<1 \%)$ & $0(-)$ & $2(<1 \%)$ & $3(<1 \%)$
\end{tabular}

Household Income** N(\%)

\begin{tabular}{lcccc}
\hline$<\$ 10,000$ & $173(15.5 \%)$ & $62(16.5 \%)$ & $187(14.6 \%)$ & $422(15.2 \%)$ \\
$\$ 10,000-\$ 20,000$ & $124(11.1 \%)$ & $60(16 \%)$ & $246(19.2 \%)$ & $430(15.5 \%)$ \\
$\$ 20,001-\$ 30,000$ & $91(8.2 \%)$ & $36(9.6 \%)$ & $202(15.7 \%)$ & $329(11.9 \%)$ \\
$\$ 30,001-\$ 40,000$ & $80(7.2 \%)$ & $54(14.4 \%)$ & $115(9 \%)$ & $249(9 \%)$ \\
$\$ 40,001-\$ 50,000$ & $53(4.8 \%)$ & $42(11.2 \%)$ & $98(7.6 \%)$ & $193(7 \%)$ \\
$\$ 50,001-\$ 75,000$ & $139(12.5 \%)$ & $42(11.2 \%)$ & $158(12.3 \%)$ & $339(12.2 \%)$ \\
$\$ 75,001-\$ 100,000$ & $118(10.6 \%)$ & $28(7.5 \%)$ & $118(9.2 \%)$ & $264(9.5 \%)$ \\
$>\$ 100,000$ & $335(30.1 \%)$ & $51(13.6 \%)$ & $160(12.5 \%)$ & $546(19.7 \%)$
\end{tabular}

Religious Affiliation N(\%)

\begin{tabular}{lllll}
\hline Affiliated & $443(40.2 \%)$ & $242(66.1 \%)$ & $587(46.4 \%)$ & $1272(46.6 \%)$ \\
Unaffiliated & $658(59.8 \%)$ & $124(32.8 \%)$ & $677(53.6 \%)$ & $1459(53.4 \%)$ \\
\hline
\end{tabular}

Note. SD = standard deviation; NHW = Non-Hispanic White; NHB = Non-Hispanic Black; *not all participants answered every demographic question; **household income is annual 
Table 2.

Means and standard deviations of social support scales (both subscales and omnibus) by racial/ethnic group

\begin{tabular}{lcccc}
\hline Mean(SD) & NHW & NHB & Hispanic & Total \\
\hline SNI People in Network & $\mathrm{N}=1118$ & $\mathrm{~N}=378$ & $\mathrm{~N}=1297$ & $\mathrm{~N}=2,793$ \\
SNI High Contact Roles & $19.56(9.5)$ & $19.1(9.11)$ & $17.34(8.8)$ & $18.46(9.2)$ \\
SNI Embedded Networks & $6.61(2.4)$ & $5.88(1.8)$ & $5.58(1.7)$ & $5.84(1.89)$ \\
SNI Total & $3.25(1.2)$ & $3.61(1.5)$ & $3.03(1.2)$ & $3.2(1.25)$ \\
SPS Attachment & $9.68(3.9)$ & $9.99(3.9)$ & $8.82(3.5)$ & $9.32(3.74)$ \\
SPS Social Integration & $13.21(2.8)$ & $12.44(2.6)$ & $12.85(2.5)$ & $12.94(2.66)$ \\
SPS Reassurance of Worth & $13.39(2.5)$ & $12.81(2.4)$ & $13.02(2.4)$ & $13.14(2.4)$ \\
SPS Reliable Alliance & $13.02(2.3)$ & $12.62(2.2)$ & $12.53(2.3)$ & $12.74(2.32)$ \\
SPS Guidance & $14.2(2.2)$ & $13.24(2.6)$ & $13.63(2.4)$ & $13.81(2.38)$ \\
SPS Opportunity for Nurturance & $12.18(2.6)$ & $11.65(2.5)$ & $12.07(2.4)$ & $12.06(2.48)$ \\
SPS Total & $80(12.3)$ & $75.95(12.3)$ & $77.68(11.9)$ & $78.4(12.21)$ \\
ISEL Appraisal & $13.58(2.7)$ & $13.06(2.6)$ & $13.23(2.7)$ & $13.35(2.69)$ \\
ISEL Belonging & $12.54(2.8)$ & $12.37(2.6)$ & $12.57(2.6)$ & $12.53(2.67)$ \\
ISEL Tangible & $13.33(2.4)$ & $12.55(2.5)$ & $12.97(2.4)$ & $13.06(2.39)$ \\
ISEL Total & $39.45(6.8)$ & $37.99(6.6)$ & $38.77(6.6)$ & $38.94(6.69)$ \\
\hline
\end{tabular}

Note. SD = standard deviation; NHW = Non-Hispanic White; NHB = Non-Hispanic

Black; SNI = Social Network Index; SPS = Social Provisions Scale; ISEL =

Interpersonal Support Evaluation Index-12; 


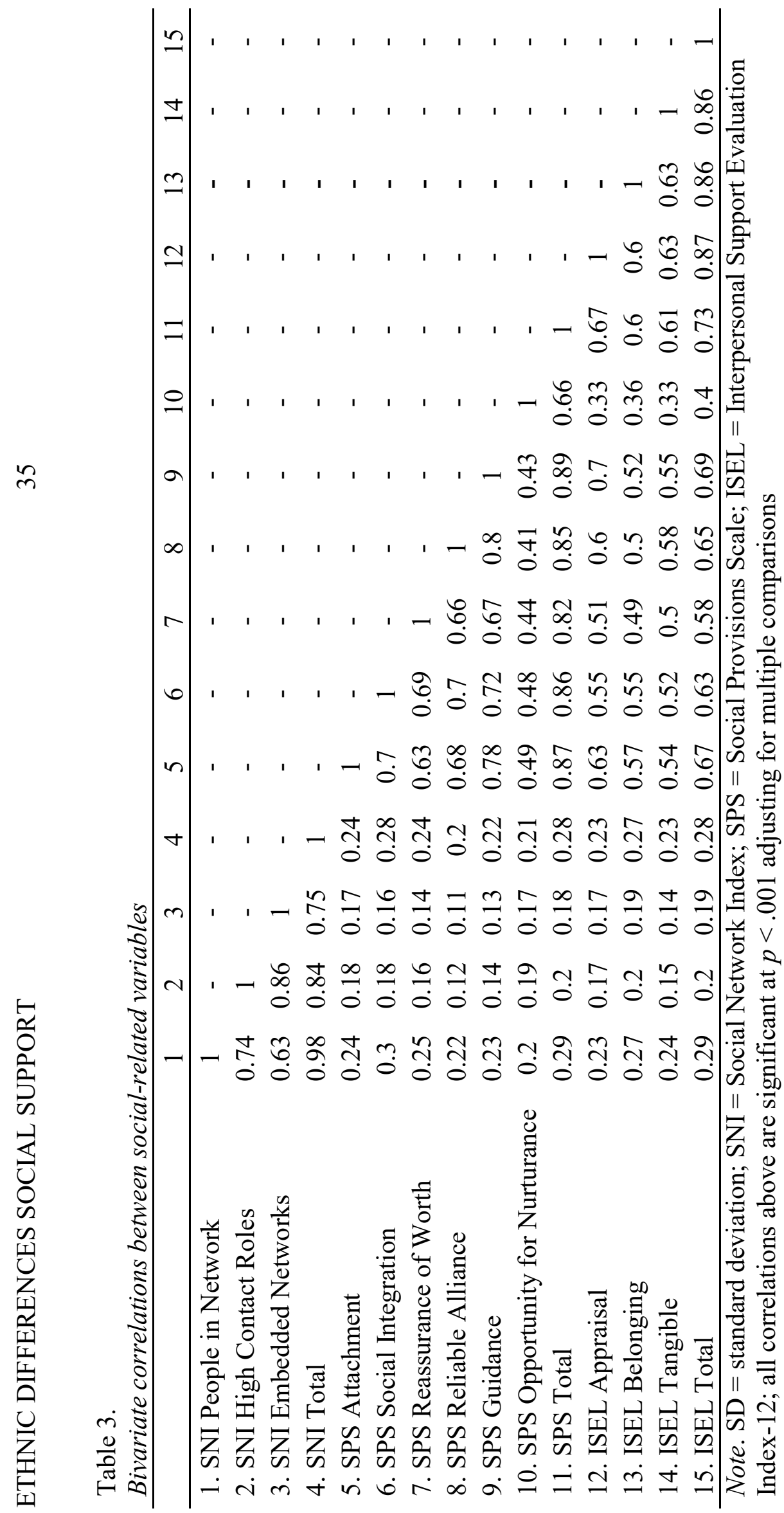




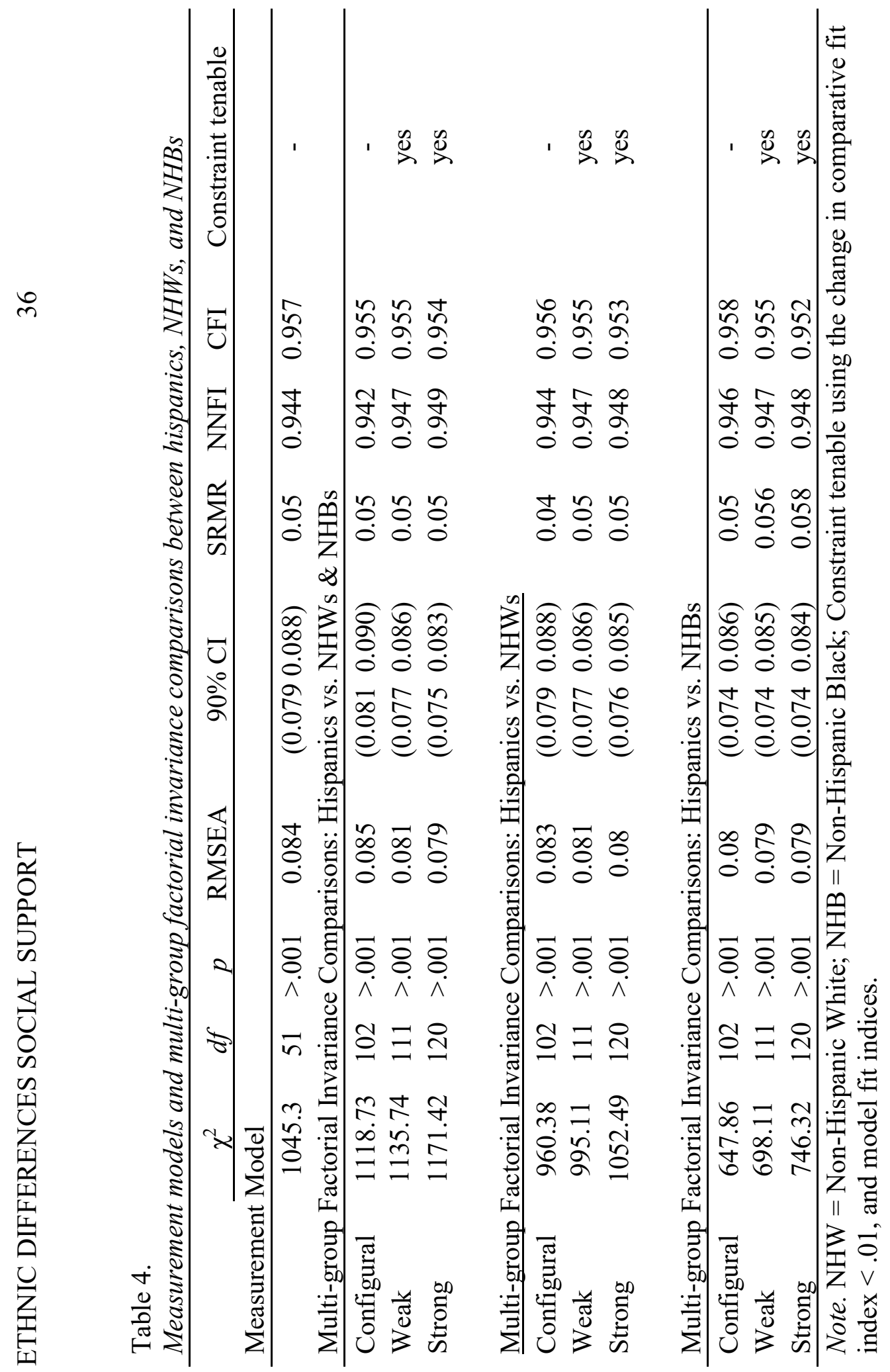




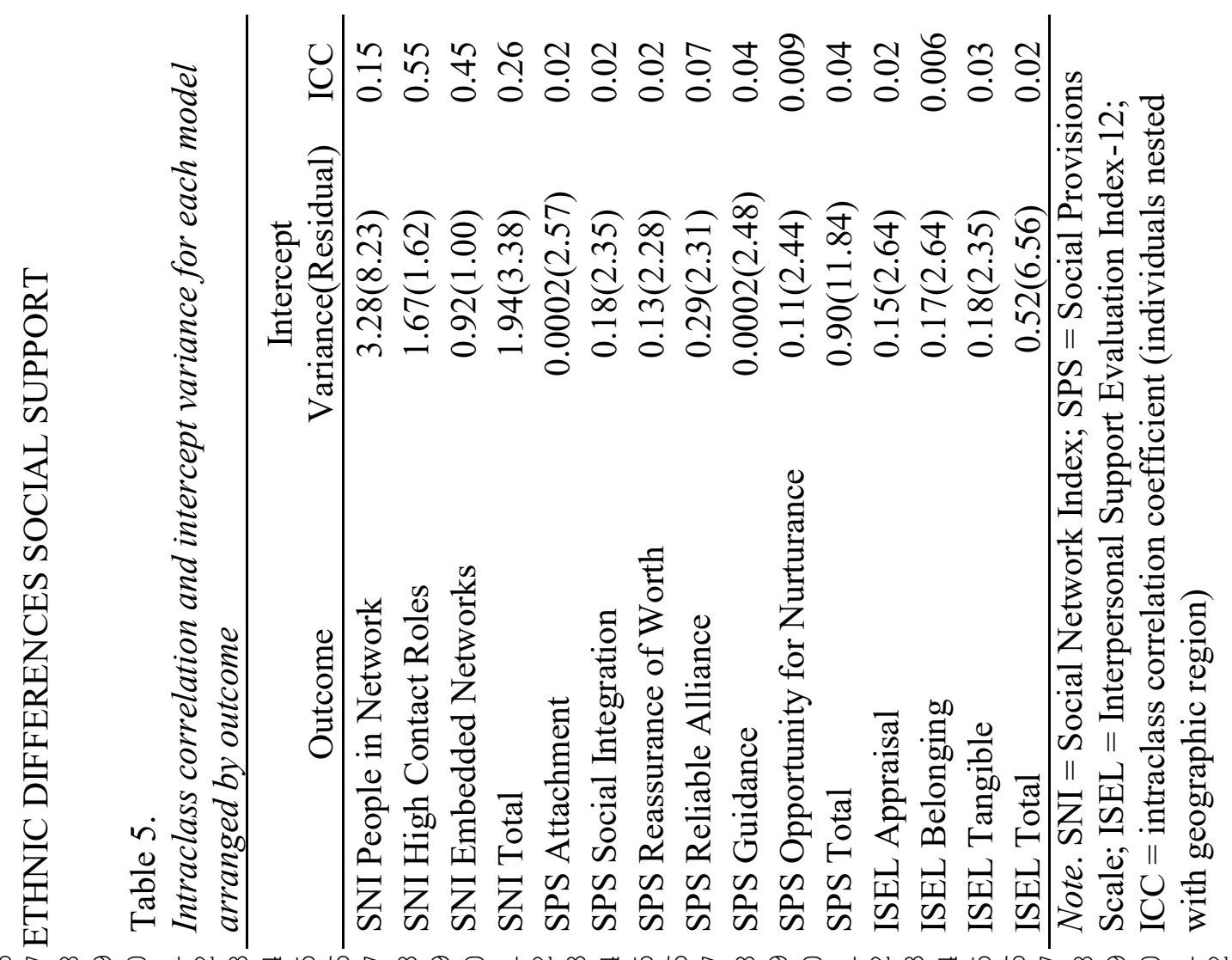




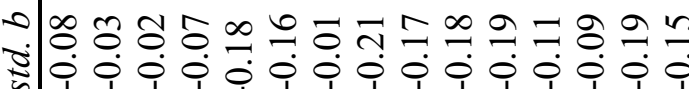

Z

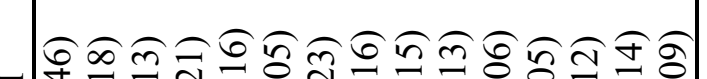

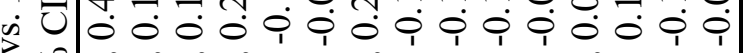

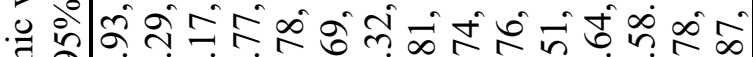

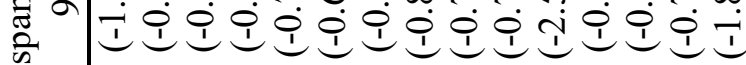

王

๓ ฺे

0 으은ㄷำ

กิ

๑ ชิ

吾

离草

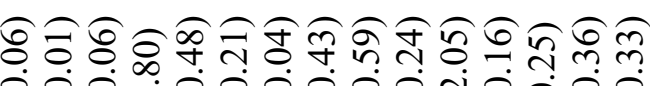

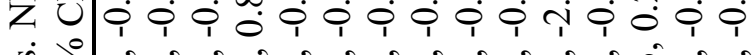
में 当 है $\bar{Z}$

0

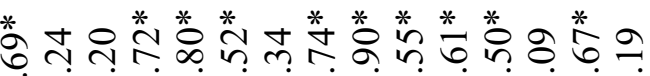
$z_{n} \cdot \vec{w}$

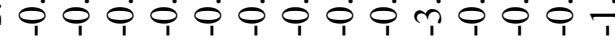

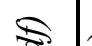

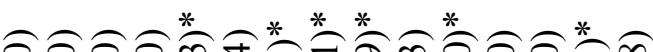
m. 